\title{
Second trimester pregnancy termination in previous cesarean section patients with unfavorable cervix: a randomized controlled clinical trial comparing 3 different methods
}

\begin{abstract}
Background: Vaginal termination of second trimester pregnancy is usually performed when complications occur. In this study, we com-pared 3 methods of vaginal termination regarding time to effacement and delivery in addition to delivery success rate.

Methods: The study was carried at Tanta University starting from April 2016 for a duration of 6 months. In all, 90 patients with previous cesarean section having different indications for second trimester vaginal termination of pregnancy were enrolled in the study. We compared 3methods: vaginal dinoprostone (PGE2), intracervical Foley's catheter, and intracervical injection of hyaluronidase enzyme (Hyal). The 90 patients were randomly distributed into 3 groups, 30 patients in each group. Time to effacement, time to delivery, and success rate of induc-tion were the outcome measures of the study.
\end{abstract}

Results: Time to effacement was $9.2 \pm 3.3$ hours in the Hyal group, $10.3 \pm 1.5$ hours in the PGE2 group, and $15.4 \pm 4.5$ hours in the Foley's catheter group $(\mathrm{P}<.001)$. Time to delivery was $14.2 \pm 3$.5 hours in the PGE2 group, followed by the Hyal group (15.7 \pm 1.7 hours $)$ and the Foleys' group $(20.12 \pm 4$.8hours $)(\mathrm{P}<.001)$. Success rate was $96.7 \%$ in the Hyal group, $90.0 \%$ in the PGE2 group, and $80.0 \%$ in the Foley's group.

Conclusion: The "Hyal" technique has the shortest time of effacement and better rate of success than the other 2 methods, but it does not give the shortest time to delivery.

Keywords: cesarean section, induction of labor, intrauterine fetal death, termination of pregnancy, time to effacement, vaginal termination
Volume 3 Issue 4 - 2017

\author{
Ahmed S El-Halwagy, Ayman Shehata \\ Aboelazm Dawood \\ Department of Obstetrics and Gynecology, Faculty of Medicine, \\ Tanta University, Egypt
}

\section{Correspondence: Ayman Shehata Aboelazm Dawood, Department of Obstetrics and Gynecology, Faculty of Medicine, Tanta University, Tanta, Egypt,}

Email ayman.dawood@med.tanta.edu.eg

Received: November 16, 2017| Published: December 27

\section{Introduction}

Induction of labor (IOL) in previous cesarean section (SC) patients with unripe cervix represents a major challenge for obstetricians to avoid fetal and maternal complications which may be catastrophic. Termination of pregnancy (TOP) in sec-ond trimester by IOL is usually performed when complications occur, such as severe preeclampsia and ruptured membranes. The other common medical indications include uncontrolled hypertension, impaired renal functions, and malignancy any-where requiring immediate management. ${ }^{1}$

Women with previous CS had an increased risk of uterine rupture than patients with unscarred uterus, so IOL in these patients should be done after thorough and detailed counseling with both patient and their relatives. ${ }^{2}$

Many studies evaluated different methods of labor induc-tion when the cervix is unfavorable, including misoprostol, transcervical insertion of Foley's catheter, double-balloon cath-eter, laminaria tents, and oxytocin intravenous drip. These methods were classified roughly into either pharmacological or mechanical methods. ${ }^{3,4}$

Although misoprostol (PGE1) is widely used for labor induction, it has a high incidence of uterine hyperstimulation and subsequent rupture uterus which is a nightmare for mis-oprostol users, especially in women with CS, so misoprostol is not recommended in those patients. ${ }^{5,6}$ On the contrary, vaginal dinoprostone is safer and had less uterine hyperstimulation and less fetal distress, but is less effective than misoprostol and somewhat expensive.?

Foley's catheter is another procedure used for mechanical IOL, which involves transcervical insertion of Foley's catheter. Foley's catheter induces labor by both mechanical dilatation and stimulating endogenous release of prostaglandins. ${ }^{8,9}$

Another new method for labor induction was tested at a low scale of populations, which is the intracervical injection of hyaluronidase. Hyaluronidase is an enzyme that increases hydrolysis of hyaluronic acid, decreases the tensile strength of cervical collagen, and hence promotes cervical softening and effacement. ${ }^{10}$

Mechanical methods apply pressure on the internal cervical os, stretch the lower uterine segment, and increase local pro-duction of prostaglandin. There is a lack of compelling evi-dence suggesting increased risk of uterine rupture because mechanical devices can also be readily removed when needed and are stable at room temperature. Regarding the question of which IOL method is suitable in women with prior CS, a recent Cochrane review stated that there was insufficient infor-mation available to conclude on the optimal method. ${ }^{4}$

In this study, we compared 3methods for second trimester cervical ripening and termination of pregnancy in previous CS patients with 
unripe cervix, which are vaginal dinoprostone, intracervical Foley's catheter, and intracervical injection of hya-luronidase enzyme. We also compared time with delivery and success rate between the 3methodologies.

\section{Patients and methods}

This study was conducted in the Department of Obstetrics and Gynecology, Tanta University, on patients attending both out-patient and inpatient units. Study protocol was approved by the Human Research Ethics Committee, Faculty of Medicine, Tanta University, before the study began. The study was held in the period from April 1 to October 1, 2016. A total of 115patients signed informed consent (IC) and were screened for the study; 25 of them were excluded due to reasons shown in Figure 1. In all, 90 patients were enrolled in the study (Figure 1).

All women were thoroughly informed about the study aims and discussion about the procedure, associated benefits and risks, and assigned written consent.

Table I Demographic data in the 3 groups

\section{Inclusion criteria}

Inclusion criteria were women with 1 lower transverse cesarean scar, singleton pregnancy, second trimester (16 to 28weeks), scar thickness $5 \mathrm{~mm}$ measured by transabdominal ultrasound, normally situated placenta, unfavourable cervix (Bishop score $<5$ ), and intact fetal membranes (Table 1).

\section{Exclusion criteria}

Exclusion criteria were women with 2 or more previous CS, classical CS, and previous uterine scar for gynecological con-ditions, eg, myomectomy, hysterotomy, congenital uterine abnormality, previous rupture uterus, uterine fibroids, pla-centa previa, premature rupture of membranes, and suspected chorioamnionitis (Table 2).

All patients were assessed by history taking and clinical examinations and were investigated by routine investigation to check for general condition. Abdominal ultrasound was done to check for fetal presentation, number of fetuses, scar thickness, placental location, and uterine anomalies or fibroids.

\begin{tabular}{lllll}
\hline Variable & Group I:PGE2 & Group II: Foley's & Group III: Hyal & P value \\
\hline Age & $27.5 \pm 5.4(17-40)$ & $28.9 \pm 5.9(18-40)$ & $29.1 \pm 3.7(19-35)$ & 0.407 \\
BMI & $26.7 \pm 3.4(19-34)$ & $27.2 \pm 3.9(20-40)$ & $27.5 \pm 4.5(19-35)$ & 0.739 \\
\hline
\end{tabular}

BMI, body mass index; Foley's, intracervical foley's catheter; Hyal, intracervical injection of hyaluronidase enzyme; PGE2, vaginal dinoprostone

Table 2 Time to effacement, time to delivery, and success rate in the 3 groups

\begin{tabular}{|c|c|c|c|}
\hline Variable & Group I:PGE2 & Group II: Foley's & Group III: Hyal \\
\hline \multicolumn{4}{|c|}{ Time to effacement, $h$} \\
\hline \multirow{2}{*}{ Base } & 27 & 24 & 26 \\
\hline & $10.4 \pm 1.5(7.5-14.1)$ & $15.4 \pm 4.7(8.1-26.1)$ & $9.2 \pm 3.4(6.4-22.3)$ \\
\hline \multicolumn{4}{|c|}{ Time to delivery, $h$} \\
\hline \multirow{2}{*}{ Base } & 27 & 24 & 26 \\
\hline & $14.2 \pm 3.6(11.2-27.2)$ & $20.1 \pm 4.8(12.9-29.5)$ & $15.8 \pm 1.8(12.6-19.2)$ \\
\hline \multicolumn{4}{|c|}{ Success (delivery) } \\
\hline Base & 30 & 30 & 30 \\
\hline Success number & 27 & 24 & 29 \\
\hline Success percent & 90 & 80 & 96.7 \\
\hline
\end{tabular}

Foley's, intracervical foley's catheter; Hyal, intracervical injection of hyaluronidase enzyme; PGE2, vaginal dinoprostone side effect was reported only in I case in group I; no serious adverse events were reported

The 90 patients included in the study were randomized into 3 study groups according to sequence of computer-generated block-random numbers.

Each group included 30patients. These groups were as follows:

Group I: vaginal dinoprostone, referred hereafter as "PGE2";

Group II: intra cervical Foley's catheter, referred hereafter as "Foley's";

Group III: intra cervical injection of hyaluronidase enzyme, referred hereafter as "Hyal."

\section{Intervention}

In Group I, PGE2 3mg tablet was applied every 12hours as a prostaglandin type to enhance cervical ripening and vaginal termination of pregnancy. If spontaneous contractions occurred every 2 minutes or if cervical score reached 9 or more, the next dose was not administered. If there were no effective uterine contractions after cervical score reaches 9 , amniotomy with oxytocin IV infusion was commenced at a rate of $1 \mathrm{mU} / \mathrm{min}$, and the infusion rate was doubled every 30 minutes until the uterine contractions become regular at 3 minute interval. If 48 hours passed without labor, it was considered method fail-ure, and in this situation, CS was offered for the patient. 


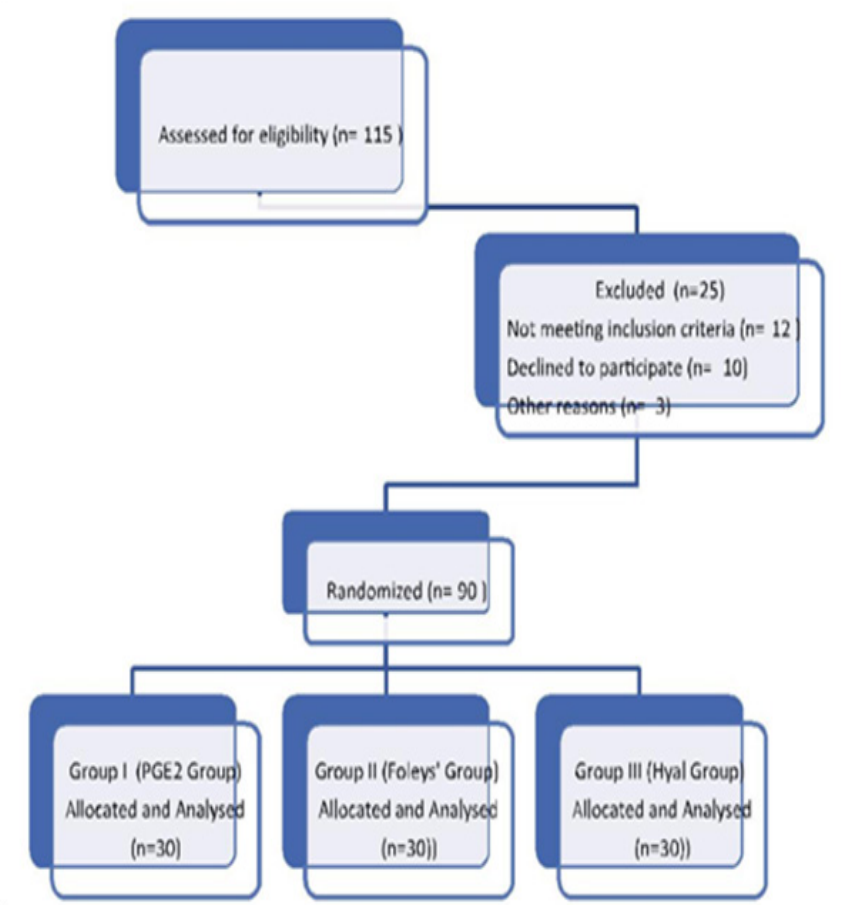

Figure I Consort flow chart.

In Group II, Foley's catheter no. 22 was inserted through the cervix under aseptic technique and pushed by uterine sound under ultrasound guide. The balloon was inflated by $30 \mathrm{~mL}$ normal saline, traction was applied to the catheter, and then it was fixed by adhesive tape to the medial side of the thigh. If it got loose, more traction was applied. The catheter was kept for 48hours if spontaneous expulsion did not occur. The catheter was removed earlier if there was spontaneous rupture of mem-branes, excessive vaginal bleeding, scar tenderness, or patient intolerance. After Foley's catheter expulsion, amniotomy with oxytocin IV infusion was commenced at a rate of $1 \mathrm{mU} / \mathrm{min}$ and the infusion rate was doubled every 30 minutes until the uterine contractions become regular at 3-minute interval. If catheter did not enhance effacement of cervix or induce labor after 48hours, it was removed and considered method failure, and under this condition, we shift to CS.

In Group III, hyaluronidase enzyme (Hylagan; Fidia Farmaceutica SpA, Italy) was used, imported by Egyptian Promoters Center for Pharmaceuticals, Cairo, which is sup-plied in prefilled syringe in $20 \mathrm{mg} / 2 \mathrm{~mL}$ solution. [AQ: 2] A dose of $0.5 \mathrm{~mm}$ was injected intracervically at 12 o'clock or at 6 o'clock position using $18 \mathrm{G}$ Disposable Spinal Needle. The pro-cedure was repeated every 12 hours for 48hours. If labor occurred during the procedure or if a cervical score of 9 was reached, the next dose was not given and amniotomy with oxy-tocin IV infusion was done, but if labor did not occur after 48hours, it was considered method failure and CS was done.

Labor was managed by the attending obstetrician and residents. Uterine activity and progress of labor were monitored by cardiotocography. The outcome parameters of the study were duration of time until effacement is reached (cervical score 9), induction to delivery interval, and rate of successful vaginal delivery.

\section{Results}

There were no significant difference

\section{Discussion}

Cohort studies suggest that for women who have had a pre-vious cesarean birth and require IOL in a subsequent preg-nancy, there are potential benefits and harms associated with the IOL. These benefits and harms may vary considerably with the method used to induce labor. Few studies addressed the hyaluronidase enzyme injection cervical ripening and termination of pregnancy. One of these studies, which had been done on 168 women comparing placebo with hyaluronidase enzyme injection, showed that IOL was achieved in $82 \%$ of patients treated with hyaluronidase enzyme com-pared with $51 \%$ in placebo. ${ }^{11}$ From another perspective, we tried to investigate the safety of different vaginal termination of pregnancy methods in patients with previous 1 cesarean section scar in the second trimester

In our study, we tried to compare the hyaluronidase enzyme injection (Hyal group), which is a method with limited data in the literature, with the other 2 standard methods for cervical ripening and termination of pregnancy. The primary objective of this study was to compare "time of effacement" between hyaluronidase enzyme injections and the other 2 well-known methods. "Time to delivery," "success rate," and "adverse events" were considered in the study as secondary objectives.

Time to effacement was $9.2 \pm 3.3$ hours in the Hyal group compared with $10.3 \pm 1.5$ hours in the PGE2 Group. The dif-ference was statistically significant $(P<.001)$ as shown in Figure 2. In addition, time to effacement was shorter than that of the Foley's group (15.4 \pm 4.5 hours). The difference was sta-tistically significant $(P<.001)$ as shown in Figure 3. Time to effacement was shorter in PGE2 than Foley's group. The dif-ference was statistically significant $(P<.001)$.

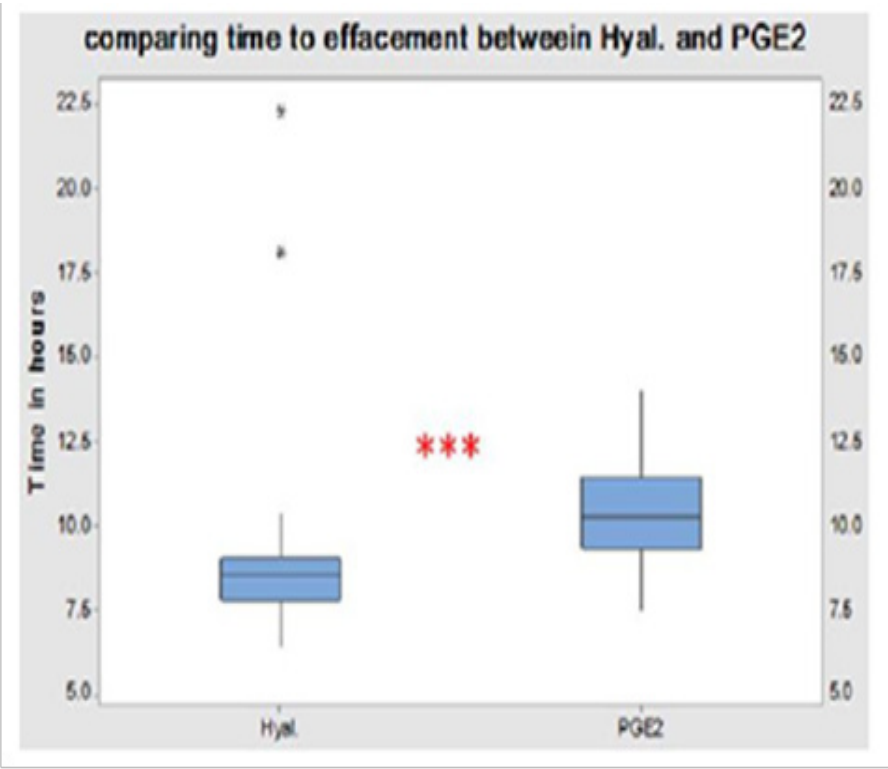

Figure 2 Comparing time to effacement between the Hyal and PGE2 groups. Hyal indicates intracervical injection of hyaluronidase enzyme; PGE2, vaginal dinoprostone.

Looking at "time to delivery," it was found that the PGE2 group has shorter time (14.2 \pm 3.5 hours) than the Hyal group (15.7 \pm 1.7 hours), which is explained by the effect of PGE2 on uterine contractility plus its cervical ripening effect. The differ-ence was statistically significant $(P<.001)$ as shown in Figure 4. 
"Time to delivery" was shorter with the Hyal Group than the Foley's group (20.12 \pm 4 .8hours). The difference was statisti-cally significant $(P<.001)$ as shown in Figure 5 .

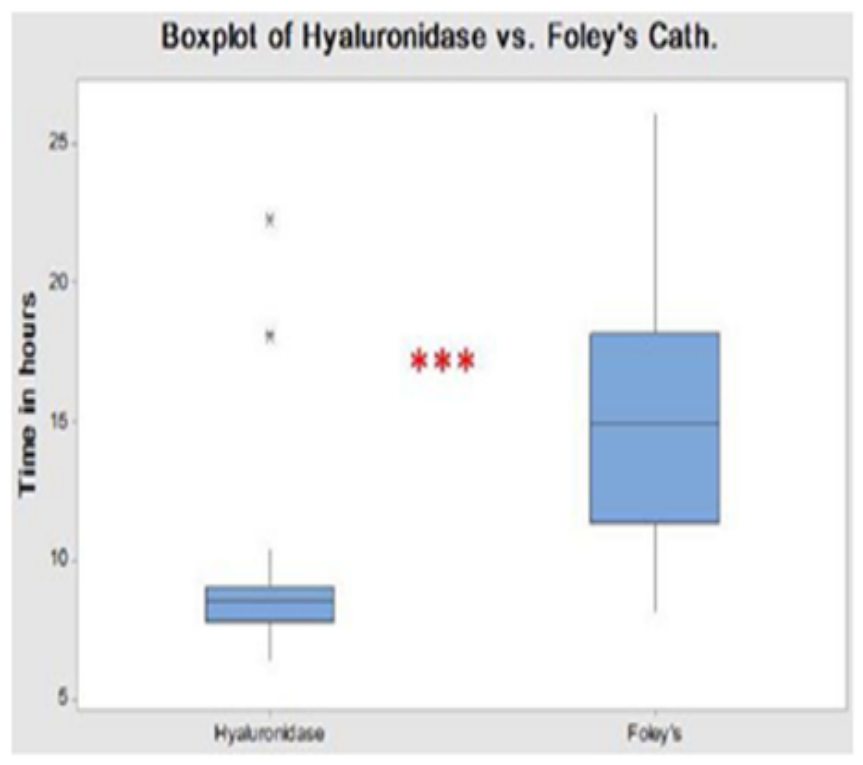

Figure 3 Comparing time to effacement between the Hyal and Foley's groups. Foley's indicates intracervical Foley's catheter; Hyal, intracervical injection of hyaluronidase enzyme.

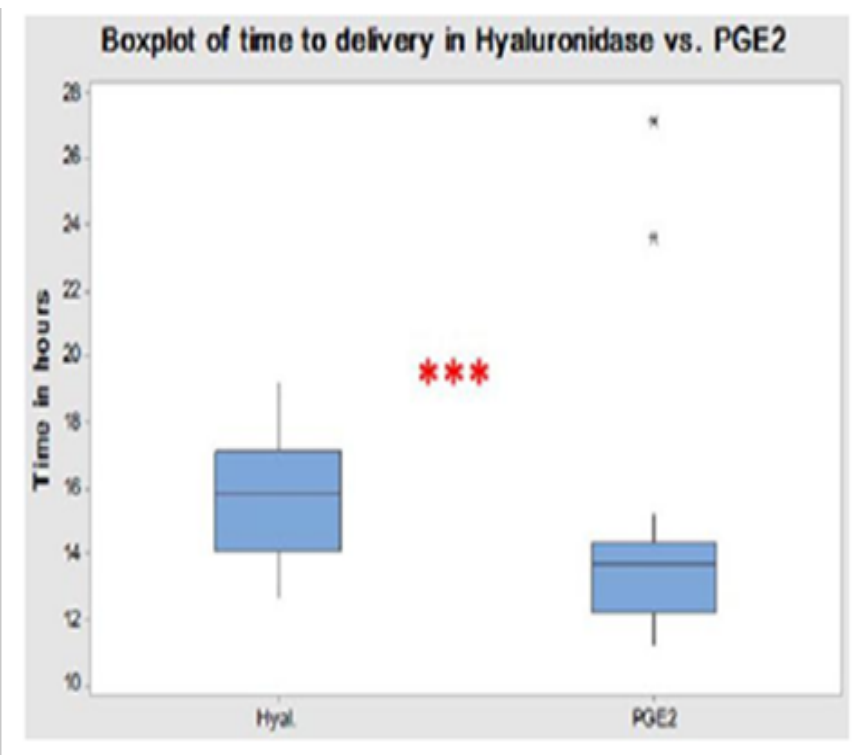

Figure 4 Comparing time of delivery between the Hyal and PGE2 groups. Hyal indicates intracervical injection of hyaluronidase enzyme; PGE2, vaginal dinoprostone.

Success rate was $96.7 \%$ (29 of 30) in the Hyal group, $90.0 \%$ in the PGE2 group, and $80.0 \%$ in the Foley's group (Figure 6). There was no statistical difference between the PGE2 group and both the Hyal and Foley's groups $(\mathrm{P}<.05)$.

Adverse events were minimal; only 1 case in the PGE2 group (3.3\%) had hyperstimulation, which was controlled by CS. No side effects were reported in the other 2 groups. No serious adverse events were reported.

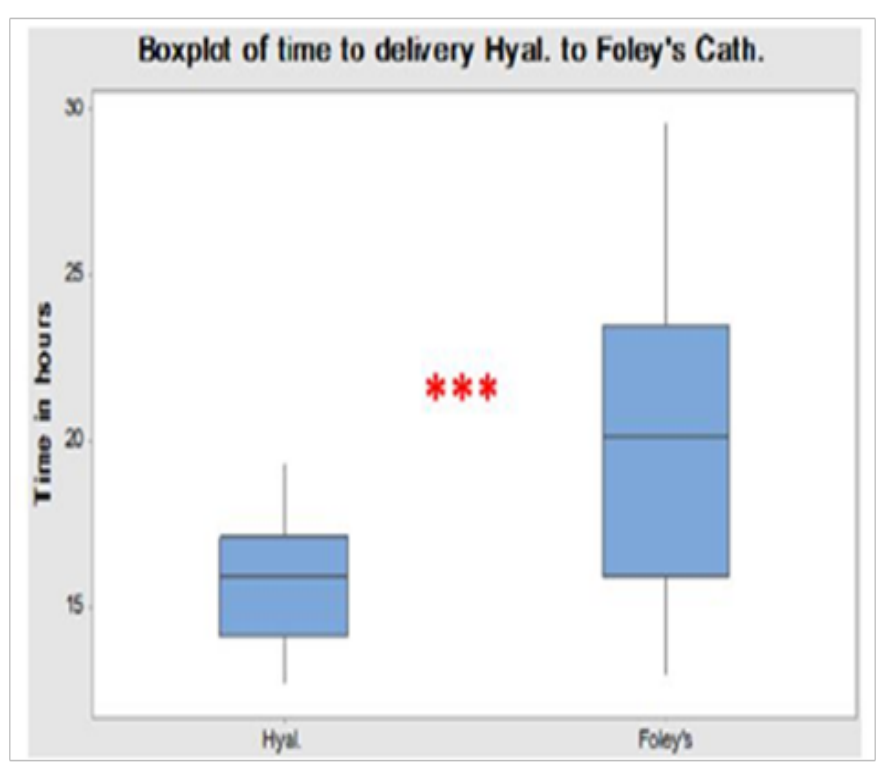

Figure 5 Comparing time of delivery between the Hyal and Foley's groups. Foley's indicates intracervical Foley's catheter; Hyal, intracervical injection of hyaluronidase enzyme.

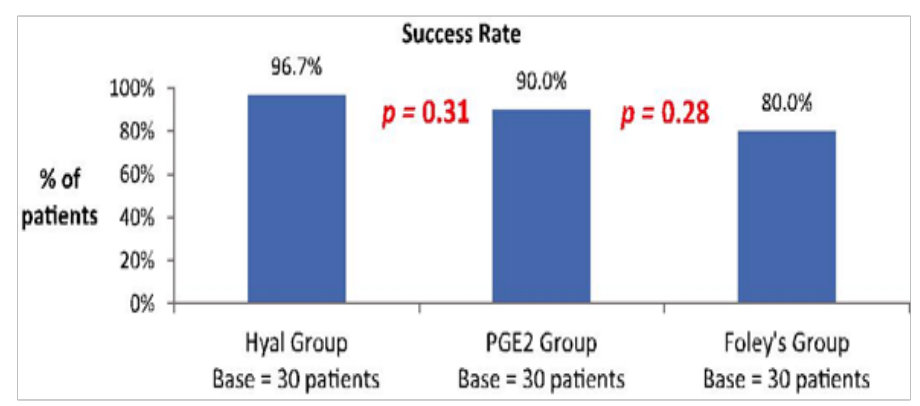

Figure 6 Success rate of the 3 methods.

\section{Conclusion}

We conclude that it is safe to go for vaginal termination of second trimester pregnancy in patients with previous 1cesarean section scar with high success rate and minimal risk. The shortest "time to cervical effacement" and saving the patient from CS are achieved by applying the "Hyal" technique than the other 2 slandered methods: "PGE2" and "Foley's." However, applying the "Hyal" technique does not give the shortest time to delivery.

\section{Acknowledgements}

None.

\section{Conflict of interest}

Author declares that there is no conflict of interest.

\section{References}

1. American College of Obstetricians and Gynecologists Committee on Obstetric Practice. ACOG Committee Opinion No. 342: induction of labor for vaginal birth after cesarean delivery. Obstet Gynecol. 2006;108(2):465-468

2. Ravasia D, Wood S, Pollard J. Uterine rupture during induced trial of labor among women with previous cesarean delivery. Am J Obstet Gynecol. 2000;183:1176-1179. 
3. Jozwiak M, Dodd J. Methods of term labour induction for women with a previ-ous caesarean section. Cochrane Database Syst Rev. 2013;3:CD009792.

4. Sananès N, Rodriguez M, Stora C, et al. Efficacy and safety of labour induction in patients with a single previous Caesarean section: a proposal for a clinical pro-tocol. Arch Gynecol Obstet. 2014;290:669-676.

5. Hofmeyr G, Gülmezoglu A, Pileggi C. Vaginal misoprostol for cervical ripening and induction of labour. Cochrane Database Syst Rev 2010;10: CD000941.

6. Austin S, Sanchez-Ramos L, Adair C. Labor induction with intravaginal miso-prostol compared with the dinoprostone vaginal insert: a systematic review and metaanalysis. Am J Obstet Gynecol. 2010;202(6):624. e1-624.e9.

7. Hughes E, Kelly AJ, Kavanagh J. Dinoprostone vaginal insert for cervical ripening and labor induction: a meta-analysis. Obstet Gynecol. 2001;97(5 Pt 2):847-855.
8. Jozwiak M, Rengerink K, Benthem M, et al. Foley catheter versus vaginal pros-taglandin E2 gel for induction of labour at term (PROBAAT trial): an open-label, randomised controlled trial. Lancet. 2011;378(9809):2095-2103.

9. Vaknin Z, Kurzweil Y, Sherman D. Foley catheter balloon vs locally applied prostaglandins for cervical ripening and labor induction: a systematic review and metaanalysis. Am J Obstet Gynecol. 2010;203(5):418-429.

10. Byers B, Bytautiene E, Costantine M, et al. Hyaluronidase modifies the biome-chanical properties of the rat cervix and shortens the duration of labor independent of myometrial contractility. Am J Obstet Gynecol. 2010;203(6):596.e1-596.e5.

11. Kavanagh J, Kelly AJ, Thomas J. Hyaluronidase for cervical ripening and induc-tion of labour. Cochrane Database Syst Rev. 2006;2:CD003097. 